\title{
We should be one!
}

\author{
Christian Schreiber, $\mathrm{MD}, \mathrm{PhD},{ }^{\mathrm{a}}$ and Peter Ewert, $\mathrm{MD}, \mathrm{PhD}^{\mathrm{b}}$
}

See related article on pages e71-8.

In the introduction to their article, Hijazi and colleagues ${ }^{1}$ make an important statement: ". . . the development of new technologies ... complemented standard surgical techniques." The introduction of percutaneous transcatheter pulmonary valve implantation (PPVI) must be considered a milestone in the treatment of patients with congenital heart disease. ${ }^{2}$ Application of PPVI has now reached nearly the 15-year mark and gained an important role in the treatment of right ventricular outflow tract lesions.

Nevertheless, the absolute number of such procedures that have been performed worldwide is reported to be $<10,000$. Therefore, the attempt to define operator and institutional requirements for the procedure is to be highly appreciated, mainly, of course, to ensure optimal quality, but additionally, to enable the team of surgeons and cardiologists to make the right treatment decision in each individual case. Currently, patients presenting with right ventricular outflow tract dysfunction can be treated with either PPVI or surgical valve replacement. ${ }^{3}$ The key for optimal treatment is individual decision making by surgeons and interventionalists. However, the operator and institutional requirements, part III, from the Society for Cardiovascular Angiography and Interventions, The American Association for Thoracic Surgery, and The Society of Thoracic Surgeons ought not be used as carte blanche!

Indications for pulmonary valve indications are mentioned. Apart from symptoms, magnetic resonance imaging criteria for PPVI should be met, among them a right ventricular end-diastolic volume of $>150 \mathrm{~mL} / \mathrm{m}^{2}$, and a pulmonary regurgitant fraction of $>40 \%$. For individual patients who do not meet these criteria, PPVI ought to be discussed in joint conferences.

The article ${ }^{1}$ mentioned that no data have been published on the average number of procedures performed by various operators and/or institutions. Given the stiff competition in many other areas, among devices and/or implantables, the picture is often blurry; thus, PPVI programs have a unique

\footnotetext{
From the Departments of Cardiovascular Surgery ${ }^{\mathrm{a}}$ and Pediatric Cardiology and Congenital Heart Disease, ${ }^{\mathrm{b}}$ German Heart Center Munich at the Technical University of Munich, Munich, Germany.

Disclosures: Authors have nothing to disclose with regard to commercial support.

Received for publication Dec 8, 2014; accepted for publication Dec 9, 2014; available ahead of print Jan 31, 2015.

Address for reprints: Christian Schreiber, MD, PhD, German Heart Center of Munich, Clinic for Cardiothoracic Surgery at the Technical University of Munich, Lazarettstrasse 36, 80636, Munich, Germany (E-mail: schreiber@dhm.mhn.de).

J Thorac Cardiovasc Surg 2015;149:1261

$0022-5223 / \$ 36.00$

Copyright (C) 2015 by The American Association for Thoracic Surgery http://dx.doi.org/10.1016/j.jtcvs.2014.12.023
}

chance at this point in time to monitor procedures and results. The Melody (Medtronic, Inc, Minneapolis, Minn) and the SAPIEN (Edwards Lifesciences, Irvine, Calif) transcatheter pulmonary valves, respectively, are currently the only available valves. Therefore, at present, the 2 companies who make these valves are the sole sources of transparency regarding valve-related information.

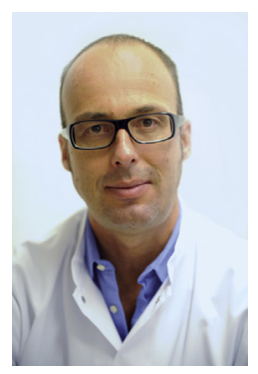

As expected, application of the PPVI technology involves a learning curve. In a publication from Lurz and colleagues, ${ }^{4}$ a significant incidence of procedural complications is reported. The operator and institutional requirements published by the 3 societies noted earlier do mention institutional requirements, as the title indicates. However, an institution that performs just 150 congenital and/or structural catheterizations per year will most likely encounter only 10 to 20 cases per year that meet the criteria for right ventricular outflow tract treatment. Given that the heart team criteria have to be met, a much lower number of actual trancatheter treatments will be undertaken, which means that operators will gain little exposure to this challenging procedure.

European institutions, including our center, teamed up with high-volume centers, a collaboration that has led to adequate exposure. ${ }^{5,6}$ In my mind, the same approach should be applied for surgical programs. With the increasing interest and involvement of surgeons in percutaneous and hybrid interventions, the threshold of more than 100 cases per year is rather low, especially given the additional fact that even extracorporeal membrane oxygenation is generally performed less than 5 times a year, which is likely not allowing for development of strong expertise in this arena either.

\section{References}

1. Hijazi ZM, Ruiz CE, Zahn E, Ringel R, Aldea GS, Bacha EA, Bavaria J, et al SCAI/AATS/ACC/STS operator and institutional requirements for transcatheter valve repair and replacement, part III: pulmonic valve. J Thorac Cardiovasc Surg. 2015;149:e71-8.

2. Jalal Z, Thambo JB, Boudjemline Y. The future of transcatheter pulmonary valvulation. Arch Cardiovasc Dis. 2014;15:S1875-2136.

3. Dilber D, Hörer J, Malcic I, Hess J, Ewert P, Eicken A. Percutaneous pulmonary valve implantation and surgical valve replacement in patients with right ventricular outflow tract dysfunction-a complementary treatment concept. Int J Cardiol. 2013;169:e3-5.

4. Lurz P, Coats L, Khambadkone S, Nordmeyer J, Boudjemline Y, Schievano S, et al. Percutaneous pulmonary valve implantation: impact of evolving technology and learning curve on clinical outcome. Circulation. 2008;117:1964-72.

5. Eicken A, Ewert P, Hager A, Peters B, Fratz S, Kuehne T, et al. Percutaneous pulmonary valve implantation: two-centre experience with more than 100 patients. Eur Heart J. 2011;32:1260-5.

6. Butera G, Milanesi O, Spadoni I, Piazza L, Donti A, Ricci C, et al. Melody transcatheter pulmonary valve implantation. Results from the registry of the Italian Society of Pediatric Cardiology. Catheter Cardiovasc Interv. 2013;81:310-6. 